\title{
Racial differences in pain treatment and empathy in a Canadian sample
}

\author{
Kimberley A Kaseweter BSc ${ }^{1}$, Brian B Drwecki $\mathrm{PhD}^{2}$, Kenneth M Prkachin $\mathrm{PhD}^{1}$
}

\author{
KA Kaseweter, BB Drwecki, KM Prkachin. Racial differences in \\ pain treatment and empathy in a Canadian sample. Pain Res Manage \\ 2012;17(6):381-384.
}

BACKGROUND: Evidence of inadequate pain treatment as a result of patient race has been extensively documented, yet remains poorly understood. Previous research has indicated that nonwhite patients are significantly more likely to be undertreated for pain.

OBJECTIVE: To determine whether previous findings of racial biases in pain treatment recommendations and empathy are generalizable to a sample of Canadian observers and, if so, to determine whether empathy biases mediate the pain treatment disparity.

METHODS: Fifty Canadian undergraduate students (24 men and 26 women) watched videos of black and white patients exhibiting facial expressions of pain. Participants provided pain treatment decisions and reported their feelings of empathy for each patient.

RESULTS: Participants demonstrated both a prowhite treatment bias and a prowhite empathy bias, reporting more empathy for white patients than black patients and prescribing more pain treatment for white patients than black patients. Empathy was found to mediate the effect of race on pain treatment.

CONCLUSIONS: The results of the present study closely replicate those from a previous study of American observers, providing evidence that a prowhite bias is not a peculiar feature of the American population. These results also add support to the claim that empathy plays a crucial role in racial pain treatment disparity.

Key Words: Empathy; Facial expression; Race; Treatment recommendations

Everas idence of inadequate pain treatment as a result of patient race has been extensively documented, yet remains poorly understood (1). Previous research has found that nonwhite patients are significantly more likely to be undertreated for all types of pain (2). Several studies have also revealed that ethnic minorities are prescribed lower doses of analgesics than nonminority patients suffering from similar medical conditions (3).

Much of the research on pain treatment disparity has focused specifically on the inadequate treatment of African Americans in the United States. Despite the finding that African Americans experience higher levels of pain than European Americans during both injury and illness, there is evidence that black individuals are less likely to receive numerous forms of pain treatment, and receive less appropriate management of congestive heart failure and pneumonia, poorer quality of hospital care, longer wait times for emergency care and fewer admissions for chest pain (4).

In a recent study, Drwecki et al (5) examined whether parallel racial differences exist in responses to facial expressions of pain. Three samples of mostly Caucasian judges - two consisting of students and the other of nursing professionals - observed video recordings of the facial expressions of light-skinned and dark-skinned individuals undergoing painful manipulations of their shoulders. Video recordings were equated for the amount of pain displayed on the basis of an index derived from the Facial Action Coding System (6). Both professional and nonprofessional samples were significantly less likely to recommend aggressive treatment for individuals with a darker skin complexion. Although the

\section{Les différences raciales dans le traitement de la douleur et l'empathie dans un échantillon canadien}

HISTORIQUE : Les données probantes sur le traitement inadéquat de la douleur en raison de la race du patient sont largement étayées, mais demeurent mal comprises. Des recherches antérieures indiquent que les patients qui ne sont pas blancs sont considérablement plus susceptibles de ne pas recevoir un traitement suffisant de la douleur.

OBJECTIF : Déterminer si les observations antérieures sur les biais raciaux à l'égard des recommandations sur le traitement de la douleur et l'empathie peuvent être généralisées à un échantillon d'observateurs canadiens et, dans l'affirmative, déterminer si les biais d'empathie sont médiateurs de la disparité dans le traitement de la douleur.

MÉTHODOLOGIE : Cinquante étudiants canadiens du premier cycle ( 24 hommes et 26 femmes) ont regardé des vidéos de patients noirs ou blancs ayant des expressions faciales de douleur. Les participants ont pris des décisions sur le traitement de la douleur et transmis leurs sentiments d'empathie envers chaque patient.

RÉSULTATS : Les participants ont démontré à la fois un biais de traitement et un biais d'empathie en faveur des blancs, affichant plus d'empathie envers les patients blancs que les patients noirs. L'empathie était médiatrice de l'effet de la race sur le traitement de la douleur.

CONCLUSIONS : Les résultats de la présente étude reprennent étroitement ceux d'une étude antérieure d'observateurs américains, fournissant des données probantes selon lesquelles le biais en faveur des blancs n'est pas une caractéristique propre à la population américaine. Ces résultats appuient également l'assertion selon laquelle l'empathie joue un rôle essentiel dans les disparités dans le traitement de la douleur selon la race.

findings were consistent with the larger body of literature on racial bias in pain-related decisions, they raise the question of the extent to which such differences in general, and specifically the difference in reactions to pain expressions, may be culture-bound because all three samples were of residents of the United States, with its relatively distinct history of and focus on 'black-white' relations. The purpose of the present study was to examine the relationship between patient race and pain treatment decisions among a sample of Canadians.

Factors potentially contributing to the racial bias in pain treatment remain poorly understood. Disparities in pain treatment may reflect racial empathy biases. Empathy is defined as a multidimensional concept with moral, cognitive, emotive and behavioural components that cultivates an understanding of others' emotional states (7). Empathy is considered to be crucial to the development of a therapeutic relationship and has been suggested to enhance diagnostic accuracy (7). Previous research has found that empathic reactions are affected by race: people report more empathy toward the pain of members of the same racial group (8). In their mostly EuropeanAmerican sample, Drwecki et al (5) found that, in addition to exhibiting significant prowhite pain treatment biases, participants also exhibited a prowhite empathy bias, reporting more empathy for white patients than black patients. Furthermore, prowhite empathy biases were highly predictive of prowhite pain treatment biases, and the magnitude of the empathy bias predicted the magnitude of the treatment bias. These findings indicated that patient race was related to

${ }^{1}$ University of Northern British Columbia, Prince George, British Columbia; ${ }^{2}$ Regis University, Denver, Colorado, USA

Correspondence and reprints: Dr Kenneth M Prkachin, Department of Psychology, University of Northern British Columbia, Prince George,

British Columbia V2N 429. Telephone 250-960-6633, fax 250-960-5744, e-mail kmprk@unbc.ca 


\section{TABLE 1}

\section{Participant demographics}

\begin{tabular}{lc}
\hline Characteristic & $\mathbf{n}(\%)$ \\
\hline Sex & $24(48)$ \\
Male & $26(52)$ \\
Female & \\
Citizenship & $47(94)$ \\
Canadian & $1(2)$ \\
American & $1(2)$ \\
Iranian & $1(2)$ \\
Mexican & \\
Ethnicity & $33(66)$ \\
Caucasian & $6(12)$ \\
First Nations & $8(16)$ \\
Asian & $2(4)$ \\
African American & $1(2)$ \\
Hispanic & \\
\hline
\end{tabular}

biases in pain treatment and that these biases were likely due to empathy biases.

This demonstration that a darker skin complexion is associated with diminished ratings of the aggressiveness of pain treatment and diminished empathy ratings, even though the facial actions on which the ratings were based were the same, is important in itself. However, it raises the equally important issue of generality. Given that the original study was performed in an American sample, it is possible that the findings represent something unique to American culture because of the historical and cultural salience of the race issue in that country. Alternatively, it is possible that the phenomenon is more general. Either possibility has important implications. The purpose of the present study was to determine whether pain treatment bias exists cross-culturally and, if so, whether empathy biases mediate the pain treatment disparity. To examine these questions, the experiment by Drwecki et al (5) was replicated in a sample of Canadian subjects. Based on the findings of Drwecki et al (5) and the expectation of generality, it was hypothesized that participants would display both a prowhite empathy bias, reporting more empathy for white patients than black patients, and a prowhite treatment bias, prescribing more pain treatment for white patients than black patients. Also consistent with the findings of Drwecki et al, it was hypothesized that racial disparities in pain treatment would be mediated by racial disparities in empathy.

Previous studies have shown that other potentially relevant variables can affect judgments of pain expression. In particular, Hadjistavropoulos et al (9) examined judgments of the pain expressions of low back pain patients. They found that unattractive patients were rated as experiencing more pain and poorer functioning than attractive patients. In an experimental study, De Ruddere et al (10) showed that the pain expressions of disliked patients were more poorly discriminated and rated as lower than those of liked patients. In two subsequent studies, separate samples of observers provided attractiveness and likeability ratings of the patients used in the present study so that the effects of those variables could be evaluated.

\section{METHODS}

\section{Participants}

In an initial study, 50 undergraduate students ( 24 men and 26 women), 17 to 29 years of age made judgments regarding the treatments they would recommend for patients and their empathy toward the patients. In two subsequent studies, 18 (nine men, nine women) and 18 (seven men, 11 women) undergraduates provided attractiveness and likeability ratings of the same patients. All participants took part in exchange for extra course credit. Individuals were recruited through an online participant pool at a Canadian university. Demographics of the original sample, including ethnicity, are presented in Table 1.

\section{Stimuli}

Four $30 \mathrm{~s}$ video clips were constructed. Each video clip contained one of four facial expressions selected from the University of Northern British Columbia/McMaster Shoulder Pain Archive (11). Facial expressions were presented for one black male, one black female, one white male and one white female. The presentation of each video clip consisted of a $5 \mathrm{~s}$ black filler, a $5 \mathrm{~s}$ title slide and a $20 \mathrm{~s}$ facial expression. Patient race was determined by patient self-report. All videos had been reliably coded for pain expression (inter-rater reliability $=0.95$ ) using the Facial Action Coding System (6). The video clips depicted individuals who participated in a previous study of shoulder pain (11). In accordance with tradition in the study of nonverbal communication, these individuals are referred to as 'senders'. The senders selected were matched according to age and the maximum intensity of their pain expression, so that any reliable differences between senders must be the consequence of factors other than pain expression intensity.

\section{Measures}

Demographics: A standard demographics questionnaire was constructed to obtain demographic information on each participant. Information collected included participants' sex, race and citizenship. Pain Treatment Recommendation scale: The Pain Treatment Recommendation scale (5) was used to assess pain treatment disparities. This four-item treatment questionnaire was designed by Drwecki et al (5) to measure multiple pain treatment decisions and was used successfully in the study on which the present study was based. After examining each patient video, participants were asked to indicate how much 'pain medication', 'physical therapy', 'pain-focused massage therapy' and 'pain-focused acupuncture therapy' they would prescribe to each patient on a 9-point Likert scale ranging from 1 'none' to 9 'a very strong amount'. Thus, scores on the Pain Treatment Recommendation scale could range from 4 to 36 . Multiple pain treatment decisions were assessed because pain treatment disparities include a large range of decisions and recommendations. This scale showed high internal reliability in the present study $(\alpha=0.91)$. Mean scores for these items were calculated to create a composite measure of pain treatment for each patient.

Empathic Concern Scale (ECS) $(12,13)$ : Participants' empathic reactions to each video clip were measured using the ECS. After viewing the video for each patient, participants were asked to indicate the extent to which they felt 'tender', 'warm', 'softhearted', 'compassionate', 'moved', 'concerned' and 'sympathetic' on a 7-point Likert scale ranging from 1 'not at all' to 7 'extremely'. Thus, scores could range from 7 to 49 . This scale showed high internal reliability in the present study $(\alpha=0.97)$. The mean ratings on this scale were calculated to create a composite measure of empathy for each sender. The psychometric properties of the ECS have been documented in previous studies, which have demonstrated that it is a coherent scale that measures empathic concern for others in need and that ECS scores are predictive of helping behaviours $(14,15)$. The ECS has been a strong predictor of helping behaviour across a number of recent studies $(16,17)$ and has been linked to the activation of neural responses indicative of empathy (18).

\section{Procedure}

Participants were brought to the laboratory individually and seated at a table facing a standard computer screen that was used for all stimulus presentations. Each subject was informed of the general nature of the experiment (to investigate how people interpret pain in others). Participants then read and signed the informed consent form and completed the demographic questionnaire. Next, participants were told 'Within this experimental laboratory you are a doctor', and were asked to wear a physician's examination jacket to signify this role. Participants were instructed to view each of the four patient videos serially and complete both the pain treatment and empathy questionnaires following each patient video clip. The order in which questionnaires were completed was determined by the participant. Each patient video clip was viewed only once, and the patient order was counterbalanced and 
determined using block randomization. Each participant was debriefed on the purpose of the study immediately following completion of the questionnaires. All questions pertaining to the study were answered in full.

In two subsequent studies, observers viewed still pictures of the senders. The pictures were selected to display neutral expressions. Observers in the first study rated the senders' attractiveness and, in the second study, likeability. The rating format was adapted from Hadjistavropoulos et al (9). Both ratings were made on 7-point Likert scales ranging from 1 'very physically unattractive/unlikeable' to 7 'very physically attractive/likeable' (7).

\section{Data analysis}

Two 2 (participant sex) $\times 2$ (sender race) $\times 2$ (sender sex) ANOVAs were used to analyze the mean ratings of items on the pain treatment and empathy scales. A mediation-moderation analysis for repeated measures designs was performed according to the method described by Judd et al (19) to investigate possible intervening roles for empathy on the principal outcome variable of pain treatment. Finally, attractiveness and likeability ratings were analyzed in separate 2 (participant sex $) \times 2$ (sender race) $\times 2$ (sender sex $)$ ANOVAs with repeated measures on the latter two factors.

\section{RESULTS}

The analysis for pain treatment demonstrated a significant main effect of sender $\operatorname{race}\left(F[1,48]=31.54, \eta_{\mathrm{p}}{ }^{2}=0.40 ; \mathrm{P}<0.001\right)$. Participants exhibited a treatment bias, prescribing a significantly higher mean pain treatment to white patients compared with black patients $(4.28 \pm 1.32$ versus $3.50 \pm 1.26)$. The analysis for empathy also revealed a significant sender race difference $\left(F[1,48]=12.73, \eta_{\mathrm{p}}{ }^{2}=0.21 ; \mathrm{P}<0.01\right)$. Participants exhibited an empathy bias in which they reported higher mean levels of empathy for white senders than black senders (3.36 \pm 1.18 versus $2.98 \pm 1.14)$. The empathy analysis also revealed a significant main effect of sender $\operatorname{sex}\left(F[1,48]=4.35, \eta_{\mathrm{p}}{ }^{2}=0.08 ; \mathrm{P}<0.05\right)$. Empathy ratings of female patients were significantly lower than those of male patients $(3.07 \pm 1.19$ versus $3.28 \pm 1.31)$.

A bivariate correlation analysis was used to examine the relationship between pain treatment decisions and empathy levels. Individual differences in empathy biases ( $\Delta$ white-black empathy) were highly positively correlated with individual differences in pain treatment biases ( $\Delta$ white-black treatment, $r[48]=0.76 ; \mathrm{P}<0.01$ ). Individuals who experienced the strongest empathy biases also exhibited the strongest treatment biases.

A mediation-moderation analysis was then conducted to further examine the relationship between racial empathy biases and pain treatment biases, using methods described by Judd et al (19). This approach is appropriate in situations such as the present study, in which differences in an outcome variable (pain treatment) are accompanied by parallel differences in a concomitant variable (empathy). The concomitant variable may moderate (relate more strongly to the outcome in one condition) or fully or partially mediate the experimental condition differences if it has causal precedence. Mediation and moderation are tested by simultaneously regressing differences in the putative outcome (pain treatment) on the comparable difference in the concomitant variable and on the centered sum of the concomitant variable. Mediation is indicated if the difference in the concomitant variable is predictive of the difference in the putative outcome; moderation is indicated if the sum is predicted by a significant sum. If the analysis shows evidence of mediation, the intercept of the resulting regression indicates the extent of the overall treatment effect that is not attributable to mediation (19).

Accordingly, difference scores were determined for white-black empathy and white-black treatment. A sum score for empathy was also calculated (white empathy + black empathy) and centered. A regression analysis was then performed using treatment difference as the dependent variable and empathy difference and empathy sum as predictors. The regression revealed that the overall model was significant
$\left(F[2,47]=32.30, R^{2}=0.58 ; P<0.01\right)$. The results of the regression indicated that empathy difference was a significant predictor of treatment difference $(t=8.015 ; \mathrm{P}<0.01)$, consistent with expectations if empathy differences mediated pain treatment differences. However, the empathy sum score was not found to be a significant predictor of treatment difference $(t=0.212 ; P=0.83)$, suggesting that empathy differences did not moderate the influence of race on pain treatment differences. Finally, the intercept of the regression model $(B=0.803, S E=0.204)$ remained significant $(t=3.937 ; \mathrm{P}<0.001)$, indicating that the effect of patient race on differences in pain treatment was only partially mediated by differences in empathy. Thus, the outcome of the analysis was consistent with the conclusion that racial differences in empathy did indeed mediate racial differences in pain treatment recommendation, although not completely.

The ANOVA of attractiveness ratings yielded only a significant sender sex difference $\left(F[1,16]=25.60, \eta_{p}{ }^{2}=0.62 ; P<0.001\right)$. Female senders were judged to be less attractive than males $(2.22 \pm 0.93$ versus $2.89 \pm 1.05)$. The ANOVA of likeability ratings resulted in significant sender sex $\left(F[1,16]=36.20 ; P<0.001, \eta_{p}{ }^{2}=0.69\right)$ and race $\left(\mathrm{F}[1,16]=7.10 ; \mathrm{P}<0.05, \eta_{\mathrm{p}}{ }^{2}=0.31\right)$ differences. Consistent with the attractiveness data, female senders $(2.99 \pm 0.96)$ were judged to be less likeable than males $(4.12 \pm 1.00)$. Black participants $(3.76 \pm 0.62)$ were judged to be more likeable than white participants $(3.35 \pm 0.89)$.

The data were reanalzyed to determine whether there was a bias attributable to the race/ethnicity of the observer. Although the sample was racially and ethnically diverse, there was an insufficient number of subjects to break the sample down using a simple white-black distinction. The sample was therefore dichotomized, distinguishing those whose ethnicity/race was Caucasian from all others. Pain treatment and empathy ratings were analyzed in 2 (observer ethnicity) $\times 2$ (patient race) $\times 2$ (patient sex) ANOVAs. The results did not differ substantially from the initial analyses. For pain treatment, the same patient race effect emerged $(\mathrm{F}[1,48]=23.88 ; \mathrm{P}<0.01)$, but there was no significant observer ethnicity effect $(P>0.10)$. The analysis for empathy revealed similar results, with a significant patient race effect $(F[1,48]=9.34 ; \mathrm{P}<0.01)$ and a nonsignificant observer ethnicity effect $(\mathrm{P}>0.10)$.

\section{DISCUSSION}

We hypothesized that observers would recommend more treatment for and report more empathy with white senders compared with black senders. Both hypotheses were supported. Participants exhibited a prowhite treatment bias, prescribing significantly more pain treatment to white patients than black patients, regardless of the fact that the patients were displaying similar levels of pain expression. This finding is consistent with the results found by Drwecki et al (5). Indeed, the mean differences and comparable effect sizes for the pain treatment difference were larger in the present study than in the study by Drwecki et al (5).

Data from the attractiveness and likeability studies suggest that the racial differences in treatment and empathy bias cannot be accounted for on the basis of those variables. Black senders were not rated as different from white senders in attractiveness. Moreover, the very small effect size value for the race difference $\left(\eta_{p}{ }^{2}=0.01\right)$ in attractiveness suggests that the failure to obtain a significant difference was not due to diminished power. Consequently, it does not appear that the findings can be interpreted as emanating from a confound with attractiveness. Although there was a significant race difference in likeability, the direction of the effect was the opposite of what would be expected if the race difference reflected a kind of 'negative halo' effect. Black senders were judged to be more likeable than white senders. Because De Ruddere et al (10) have shown experimentally that dislikeability is associated with diminished pain ratings, it would appear that whatever underlies the racial differences in pain treatment and empathy in the present study, it is unlikely to be a mere consequence of likeability.

These findings support the idea that pain treatment bias is a phenomenon that can be found cross-culturally, and further support the idea that patient race is sufficient to cause biases in pain treatment. A 
potential limitation to the study by Drwecki et al (5) was its exclusive reliance on a sample drawn from an American population. The present study indicates that the same influence of skin colour on pain treatment recommendations and empathy holds in a sample drawn from one Canadian region. Given the vast size and regional cultural differences of both countries, it would be premature to argue that the differences observed generalize broadly to both the American and Canadian population, let alone to widely divergent regions and cultures around the world. What the findings do illustrate, however, is that the biases in pain evaluation and pain-related empathy are not a peculiarly American phenomenon. This should give comfort to citizens of neither country.

Also consistent with the results of Drwecki et al (5), a strong positive correlation was found between racial empathy biases and racial pain treatment biases, in which the magnitude of the empathy bias one experienced predicted the magnitude of the treatment bias they exhibited. Individuals who exhibited strong empathy biases also exhibited strong pain treatment biases; the stronger the empathy bias, the stronger the pain treatment bias. Mediation analyses supported the suggestion that, more than being merely a pain treatment correlate, differences in empathy toward the two races mediated the effect of race on pain treatment. Using a simple experimental perspective-taking intervention (asking participants to imagine how the sufferers are feeling and how the pain is affecting their lives), Drwecki et al (5) showed that it is possible to eliminate the racial disparities in both pain-related empathy and treatment recommendations. This issue was not addressed in the present study, but there is no reason to suspect that this effect would not cross national borders.

\section{SUMMARY}

Participants demonstrated both a prowhite treatment bias and a prowhite empathy bias, with participants reporting more empathy for white patients than black patients, and prescribing more pain treatment for white patients than black patients. In addition, a strong positive correlation was found between racial empathy biases and racial pain treatment biases, and empathy was found to mediate the effect of race on pain treatment. The results from the present study, taken in combination with the results reported by Drwecki et al (5), add support to the claim that empathy plays a crucial role in racial pain treatment disparity. Unlike participants in the study by Drwecki et al, who were white undergraduate students and registered nurses in the United States, participants in the present study were a cross-cultural group of Canadian undergraduate students. Empathy levels and pain treatment decisions were not influenced by participant ethnicity (white or nonwhite). The finding that both white and nonwhite Canadian citizens display similar empathy and treatment biases further supports the belief that pain treatment bias is a cross-cultural phenomenon.

\section{Limitations and future directions}

There are potential limitations that should be considered when interpreting the results of the present study. The stimuli used included both a narrow range of ethnicities and a small sample size within each ethnicity. The present study was also limited by the narrow range of participants used - all undergraduate students with unknown experience in actual health care settings. Generalizability to actual health care providers may, thus, be questioned, although our participants' performance did, in fact, resemble that of practicing nurses in the Drwecki et al (5) study. Future studies should consider including a wider range of races and ethnicities in the patient video clips, as well as broadening the participant sample. In addition, this topic was examined using a highly controlled laboratory experiment to maintain experimental control. By doing so, the generalizability of the results to real-world settings may be somewhat compromised.

Although the findings from the present study provide evidence that a prowhite treatment bias does exist cross-culturally, it does not suggest that nothing can be done to reduce the treatment bias. For example, Drwecki et al (5) found that a simple perspective-taking task reduced racial disparities by upwards of 55\%. This finding is promising and an important step forward in reducing treatment disparity. Future studies may wish to examine whether perspective taking can reduce pain treatment bias across ethnicities. In addition, future studies should further investigate possible solutions to better assist health care professionals in removing racial bias when making pain treatment decisions.

ACKNOWLEDGEMENTS: The authors thank Josh Rash for assisting in numerous ways with the present study.

FUNDING AND CONFLICTS OF INTEREST: The present research was supported by a grant from the Social Sciences and Humanities Research Council of Canada. The authors are unaware of any commercial associations or arrangements that could be interpreted as conflicts of interest in relation to the present research.

\section{REFERENCES}

1. Cintron A, Morrison R. Pain and ethnicity in the United States: A systematic review. J Palliative Med 2006;9:1454-73.

2. Burgess D, van Ryn M, Crowley-Matoka M, Malat J. Understanding the provider contribution to race/ethnicity disparities in pain treatment: Insights from dual process models of stereotyping. Pain Medicine 2006;7:119-34.

3. Weisse C, Foster K, Fisher E. The influence of experimenter gender and race on pain reporting: Does racial or gender concordance matter? Pain Medicine 2005;6:80-7.

4. Fiscella K, Franks P, Doescher MP, Saver BG. Disparities in health care by race, ethnicity, and language among the insured: Findings from a national sample. Medical Care 2002;40:52-9.

5. Drwecki BB, Moore CF, Ward SE, Prkachin KM. Reducing racial disparities in pain treatment: The role of empathy and perspectivetaking. Pain 2011;152:1001-6.

6. Ekman P, Friesen WV. Facial action coding system: A technique for the measurement of facial movement. Palo Alto: Consulting Psychologists Press, 1978.

7. Mercer SW, Reynolds W. Empathy and quality of care. Brit J Gen Pract 2002;52:9-12.

8. Avenanti A, Sirigu A, Aglioti SM. Racial bias reduces empathic sensorimotor resonance with other-race pain. Current Biol 2010;20:1018-22.

9. Hadjistavropoulos T, McMurtry B, Craig KD. Beautiful faces in pain: Biases and accuracy in the perception of pain. Psychol Health 1996;11:411-20.

10. De Ruddere L, Goubert L, Prkachin K, Stevens M, Van Ryckeghem D, Crombez G. When you dislike patients, pain is taken less seriously. Pain 2011;152:2342-7.

11. Prkachin KM, Solomon PE. The structure, reliability and validity of pain expression: Evidence from patients with shoulder pain. Pain 2008;139:267-74.

12. Batson C, Dyck JL, Brandt J, et al. Five studies testing two new egoistic alternatives to the empathy-altruism hypothesis. J Pers Soc Psychol 1988;55:52-77.

13. Batson CD, Early S, Salvarani G. Perspective taking: Imagining how another feels versus how you would feel. Pers Soc Psychol Bull 1997;23:751-8.

14. Batson C. Prosocial motivation: Is it ever truly altruistic? In: Berkowitz L, ed. Advances in Experimental Social Psychology, Volume 20. San Diego: Academic Press, 1987:65-122.

15. Batson, C. The altruism question: Toward a social-psychological answer. Hillsdale: Lawrence Erlbaum Associates Inc, 1991.

16. Batson C. Altruism and prosocial behavior. In: Gilbert DT, Fiske ST, Lindzey G, eds. The Handbook of Social Psychology, Volumes 1 and 2, 4th edn. New York: McGraw-Hill, 1998:282-316.

17. Batson C. Altruism in Humans. New York: Oxford University Press, 2011.

18. Lamm C, Batson C, Decety J. The neural substrate of human empathy: Effects of perspective-taking and cognitive appraisal. J Cogn Neurosci 2007;19:42-58.

19. Judd CM, Kenny DA, McClelland GH. Estimating and testing mediation and moderation in within-participant designs. Psychol Methods 2001;6:115-34. 


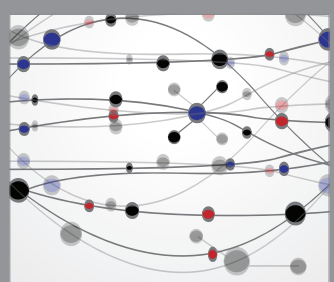

The Scientific World Journal
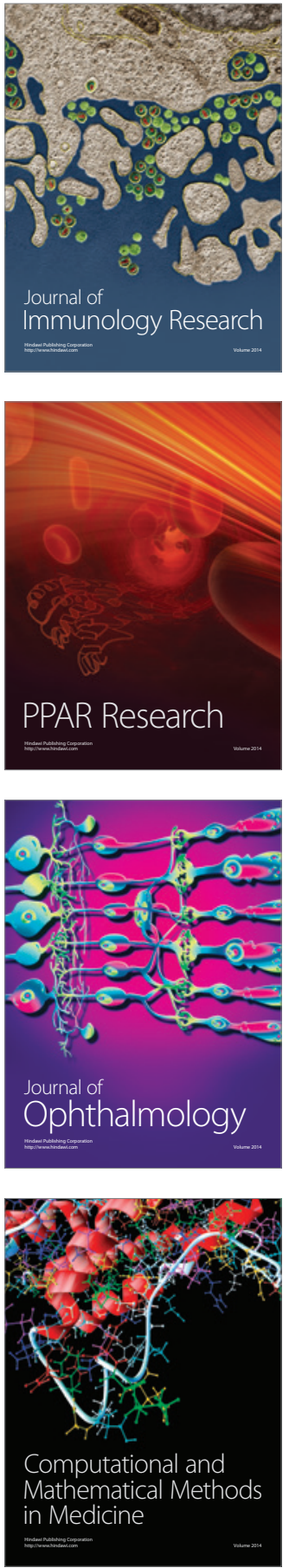

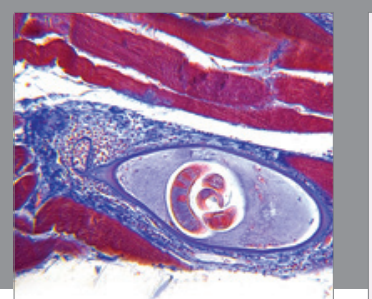

Gastroenterology Research and Practice

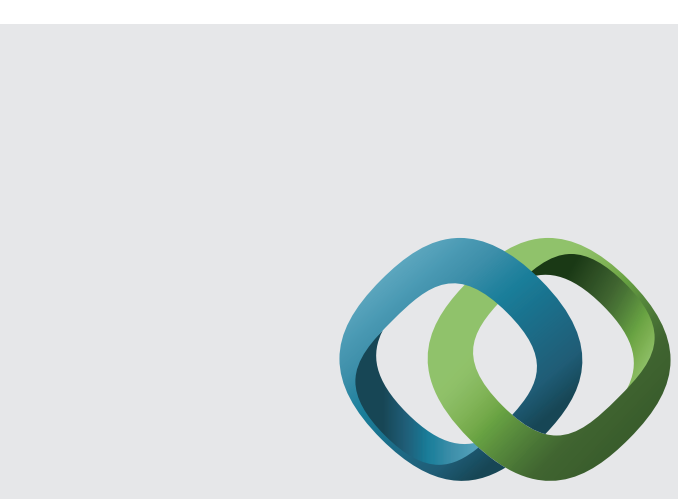

\section{Hindawi}

Submit your manuscripts at

http://www.hindawi.com
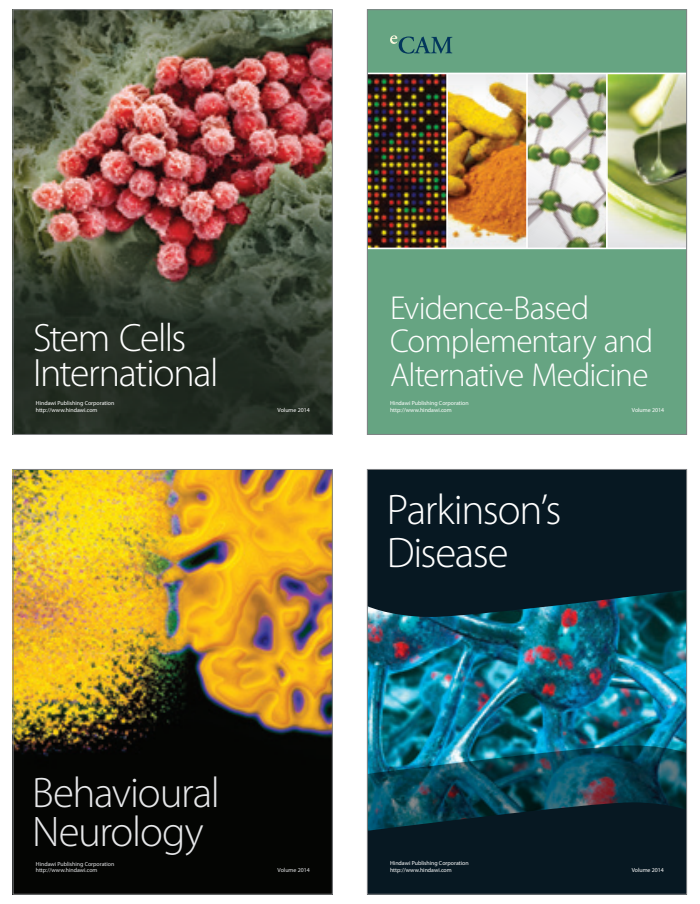
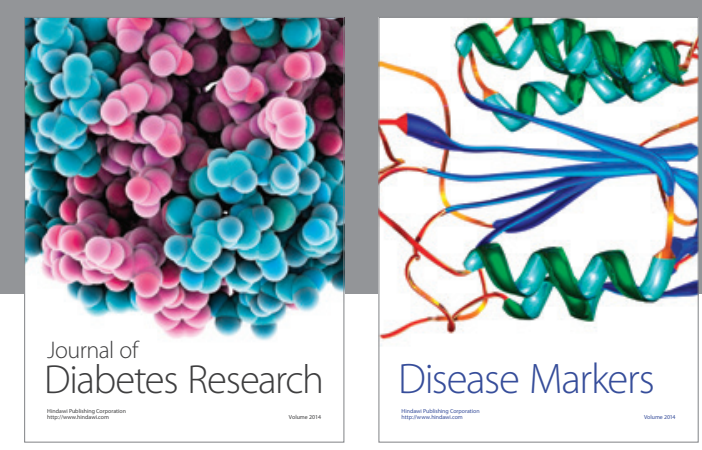

Disease Markers
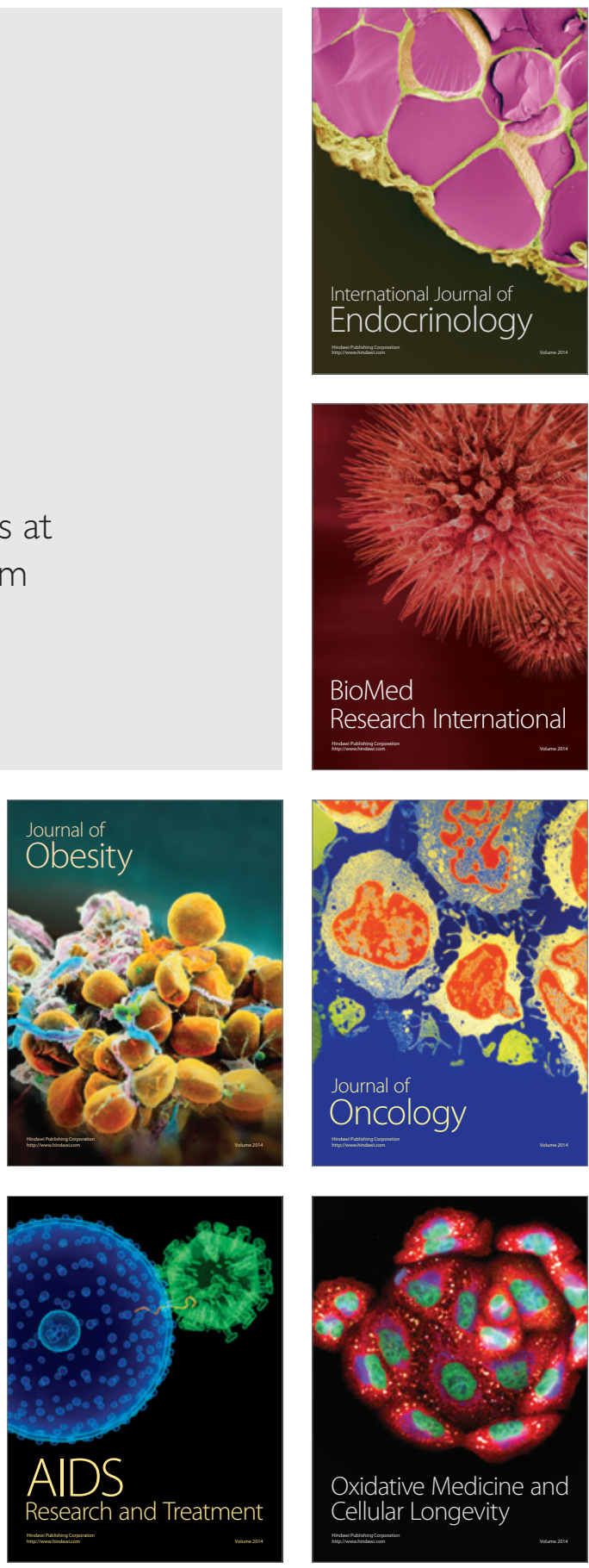